\title{
Los cuentos de Canterbury, de XXX a clasificación A
}

\author{
Mario MuRgia ELIZALDE \\ Universidad Nacional Autónoma de México
}

La admiración que Los cuentos de Canterbury, de Geoffrey Chaucer, ha despertado desde su finalización en los últimos años del siglo XIV es tan grande como los esfuerzos de difusión, traducción y adaptación que, desde entonces, han realizado diferentes escritores y eruditos. Según dicen algunos, Los cuentos de Canterbury incluso le valen a Geoffrey Chaucer el honor de ser el poeta y escritor más importante del mundo angloparlante después de Shakespeare. El poeta, crítico y dramaturgo John Dryden, ya en el siglo XVIII, lo consideraba piedra de toque de la tradición literaria inglesa, mientras que a fines del siglo XIX y a todo lo largo del XX, los estudios chaucerianos adquirieron gran relevancia en universidades e institutos del mundo anglófono y de otras latitudes.

No obstante, la censura y las expurgaciones a las que se ha enfrentado la obra de Chaucer en sus modernizaciones y traducciones es tan ostensible como común: los fabliaux ${ }^{1}$ relatados por personajes como el molinero, el administrador y la comadre de Bath, por ejemplo, han sido víctimas de la "prudencia" de diversos traductores y editores, incluso en ediciones realizadas hace menos de un par de décadas.

Las traducciones de Los cuentos de Canterbury al castellano no son numerosas; ${ }^{2} \sin$ embargo, en ellas puede advertirse toda una gama de registros que presentan desde una gran fidelidad al texto original en inglés medio hasta el completo enmudecimiento de pasajes pícaros, juguetones y hasta vulgares que dan carácter y circunstancia a diferentes personajes de Los cuentos de Canterbury y a sus respectivos relatos. La intención de este breve ensayo será explorar los casos de fidelidad, atenuación y censura de un par de cuentos y algunas secciones del poema en las versiones al castellano que ofrecen las

\footnotetext{
${ }^{1}$ Según la Princeton Encyclopedia of Poetry and Poetics, un fabliau es "un relato breve en verso, generalmente escrito en pareados octosilábicos, que relata un incidente cómico o vulgar de la vida entre los miembros de la clase media" (1990: 270).

${ }^{2}$ El catedrático en literatura inglesa de la Universidad de Vigo, Jorge Luis Bueno Alonso, comenta sobre las obras de Chaucer traducidas al castellano: "La nómina de obras de Chaucer traducidas al español es bien reducida. De su monumental The Canterbury Tales tenemos la magnífica versión de Pedro Guardia (1995) y la notable de Jordi Lamarca (1984). De otras obras, destacan The Parliament of Fowles en la ajustada aunque prosaica versión de Luis Costa (1982), The House of Fame en la reciente y no muy afortunada versión de Antonio León y Jesús Serrano (1999) y Troilus and Criseyde en versión final en prosa de Antonio León (1985) [...]” (2001: 1).
} 


\section{$26 \square$ LOS CUENTOS DE CANTERBURY}

editoriales Cátedra, Gredos, Porrúa y la colección Erasmo de textos bilingües de la casa editorial Bosch. De esta guisa, se pretende dar pie a una crítica más o menos objetiva de algunos de los procesos de traducción del texto chauceriano, así como a una reflexión sobre el papel del traductor en la tan común práctica de la censura literaria.

En 1998 apareció una colección de poemas intitulada Birthday Letters del famoso poeta inglés Ted Hughes. El libro quiso ser una suerte de recuento y reflexión poética de la vida del poeta junto a su igualmente afamada esposa Sylvia Plath, ella misma escritora y artista de gran talento y visión poética. Los versos iniciales del poema rezan así: "Whan that Aprille with hise shoures soote / The droughte of March hath perced to the roote...' / At the top of your voice, where you swayed on the top of a stile / [...] you declaimed Chaucer / to a field of cows" (1998: 51, vv. 1-7). ${ }^{3}$ Quien recita es, por supuesto, Plath en medio de un arrebato bucólico que, desde el punto de vista de Hughes, la hacer ver casi heroica, poseedora de una sinceridad poética profunda, pero al mismo tiempo atacada por un acre aire de ridiculez, dado el carácter animal de sus escuchas y lo inusitado de la selección lírica. Continúa el poema: "It [la voz de Plath] must have sounded lost. But the cows / Watched, then approached: they appreciated Chaucer. / [...] You were rapt. And the cows were enthralled" (vv. 13-14, 18). ${ }^{4}$

Encuentro que, en los versos anteriores, Ted Hughes hace mucho más que esbozar una sátira reverencial de su esposa muerta: muy probablemente, aunque tal vez de manera inadvertida, el poema de Hughes ilustra la recepción que se ha tenido de la obra de Chaucer - en especial de Los cuentos de Canterbury - a través de muchas generaciones de poetas, críticos, escuchas, lectores y, por supuesto, traductores. Sin un afán grosero de bovinización, bien se puede sugerir que muchos de quienes recibimos a Chaucer - ya sea en el original "inglés medio", en modernizaciones o en traducciones - compartimos el entusiasmo de la vacas de Hughes: apreciamos sus versos con embeleso, cautivados por su métrica y su ritmo, sus agudas descripciones, la complejidad narrativa de sus relatos, y el encanto, a veces más que colorado, de sus contenidos. No obstante, con ojos de transparencia del todo bovina, nos limitamos en muchas ocasiones a leer a medias —o comprender a medias - el lejano mundo medieval chauceriano, víctimas de los arrobados alaridos de modernizadores o traductores que, tal vez sin desearnos mal alguno, ahogan los ecos pícaros del poeta del siglo XIV al ejercitar la censura bienintencionada, aunque acaso maldecida.

Los cuentos de Canterbury cuentan con una larga historia de censura, adaptación y reescritura que, casi invariablemente, ha tenido como resultado la recaracterización —e incluso la descaracterización - de sus personajes más famosos y memorables. En una selección de varios de los Cuentos, que aparecieron como "modernizaciones"

\footnotetext{
3 "Las suaves lluvias de abril han penetrado hasta lo más profundo de la sequía de marzo..." / A voz en cuello, insegura en lo alto de una escalerilla [...] / declamabas a Chaucer / ante un prado lleno de vacas. Mi traducción.

4 "De seguro sonó perdida, pero las vacas / te observaron, para luego acercarse: apreciaban a Chaucer. / [...] Estabas arrobada; y las vacas, extasiadas". Mi traducción.
} 
aptas para el lector inglés del siglo XVIII, ${ }^{5}$ la editora Betsy Bowden (1991) presenta, por ejemplo, una versión anónima del "Cuento del molinero" (1791), la cual incluye una sesuda introducción en la que se justifican las francas alusiones sexuales y el florido hablar del personaje. Curiosamente, esta versión fue publicada tan sólo un par de años antes que la de William Lipscomb (1754-1842), quien, en un prefacio para su edición de 1795, defiende la exclusión de los vulgares cuentos del molinero (una vez más) y del administrador.

La censura de los cuentos de Chaucer no es un fenómeno exclusivo del siglo XVIII ni de Inglaterra. Entre 1874 y 1915, el padre de la censura norteamericana, Anthony Combstock, fundador de la Sociedad Neoyorkina para la Supresión del Vicio (1872), logró prohibir en Estados Unidos aproximadamente ciento veinte toneladas de materiales escritos, entre los cuales estaban, por supuesto, Los cuentos de Canterbury. Incluso ya en este nuevo siglo, ni siquiera la supuesta apertura de ciertos medios, artistas y compañías editoriales ha bastado para salvar a Chaucer de las tijeras de censores que, paradójica o contradictoriamente, desdibujan a los personajes chaucerianos en un atropellado afán de difusión: apenas el año pasado, un rapero canadiense, Baba Brinkman, decidió trasladar a Chaucer del ámbito literario al musical dado que "todos los temas del rap están contenidos en los cuentos: celos, ira, codicia, lujuria". Y, sin embargo, el músico y maestro en estudios chaucerianos agrega: "El cuento del molinero en particular contiene muchas referencias a los genitales y al humor corporal. Tuvimos que censurar algunas partes para que resultara adecuado para los niños" (Parkinson, 2005). Parece que el público receptor de Chaucer, incluidos los niños, bien puede conservar su inocencia ante temas por demás espinosos, siempre y cuando no se vea expuesto a ellos a través del variopinto lenguaje poético de personajes provenientes de la Inglaterra del siglo XIV.

Los ejemplos anteriores constituyen una prueba fehaciente de los procesos literarioculturales que han ayudado, no obstante, a fijar la obra más importante de Chaucer en la mente de los lectores y del público general de habla inglesa. A pesar de la distancia geográfica y temporal, estos procesos, sobre todo en el ámbito literario, encuentran en la tradición hispánica parangones notables, los cuales vale la pena conocer y explorar, dados los relativamente escasos intentos de traducción al castellano de Los cuentos de Canterbury, la mayoría de ellos, si no es que todos, llevados a cabo en prosa.

Prácticamente todos los traductores de Chaucer a nuestra lengua coinciden en que una de las mejores maneras de salvar las distancias lingüísticas que se extienden entre el dialecto londinense del siglo XIV y el castellano moderno es a través de la prosificación. Dice Pedro Guardia Massó, editor y traductor de la versión de Cátedra: "Realmente sólo se puede saborear plenamente a Chaucer leyéndolo en inglés medieval. Sin embargo, existe otra opción: traducir en prosa. Con un objetivo primordial: el de desvelar el significado del original de la forma más literal posible, de modo que

\footnotetext{
${ }^{5}$ Eighteenth-Century Modernizations of the Canterbury Tales. La editora es además profesora de literatura inglesa en la Universidad de Rutgers, Nueva Jersey.
} 


\section{$28 \square$ LOS CUENTOS DE CANTERBURY}

la traducción sea un reflejo de su contenido. Ésta es la opción que se ha tomado en el presente caso" (2001: 59).

Desde un principio, Massó pone en clara desventaja a quienes no tienen acceso al conocimiento de lo que llama, de manera harto general, "inglés medieval", además de que se cura en salud sosteniendo que la prosa acerca al lector al "sentido" más exacto del original. Quienes se han enfrentado a la traducción de poesía, sobre todo de poemas extensos, saben que Massó puede tener razón; sin embargo, cuando también en su introducción el editor discute la imposibilidad de traducir lo que califica de "ironía verbal" en Los cuentos de Canterbury, en el lector empiezan a generarse sospechas sobre si lo que impide la traducción "literal" serán únicamente los aspectos formales del texto. Al discutir las menciones de lo que él llama la zona sexual femenina en el cuento de la comadre de Bath, Massó dice lo siguiente: "el empleo de numerosos sinónimos para expresar el mismo concepto establece una gradación irónica según el vocablo que se utilice" (54). A continuación hace una lista de términos como "myn instrument", "bele chose" y "privee place", todos eufemismos que no presentan mucho problema de impudicia al traducirse literalmente como "mi instrumento", "cosa bella" y "parte privada", respectivamente. No obstante, al referirse al término "queynte", Massó ofrece la opción de "aparato genital", cuando el equivalente en castellano sería "coño" (cunt, término que, por cierto, no se consideró obsceno sino hasta el siglo XVII).

La prudencia entre los traductores de Chaucer al castellano, sin embargo, no es privativa de Massó o de las adaptaciones del cuento de la malhablada comadre de Bath. Desde su prólogo, Los cuentos de Canterbury ha enfrentado una suerte de suavización en cuanto a las alusiones irónicas que ya ha señalado Massó y que, en definitiva, son instancia del ojo clínico que poseía Chaucer para analizar a los representantes de diversos medios sociales en el contexto de una peregrinación, con las ventajas de caracterización que esto representa. Por ejemplo, Chaucer retrata a su deshonesto aunque elocuente bulero diciendo que "No berd hadde he, ne nevere sholde have; / As smothe it was as it were late yshave. / I trowe he were a geldyng or a mare" (1979: 23, vv. 689-692). El poeta centra aquí su atención en un carácter afeminado que Massó, dando al traste con la metáfora que relaciona al bulero con un caballo castrado e incluso con una yegua, traduce simplemente como: "Lo tomé por castrado o invertido" (83). Jesús L. Serrano Reyes y Antonio R. León Sandra, en la edición de Gredos, van más allá haciendo el pasaje quizá aun más prosaico y llamando al bulero "eunuco u homosexual" (2004: 82) con términos casi médicos. Pero la versión más colorida, no por su respeto al original, sino por su evidente tropiezo, es la de Juan G. De Luaces, para la edición de Porrúa, quien pone en pluma del poeta lo siguiente: "Y su montura era, a lo que recuerdo, un caballo capón o acaso, una yegua" (1992: 10). Los animales quedan, sí, pero no caracterizan al bulero: sólo lo transportan. Para este traductor el bulero podrá ser corrupto por vender reliquias falsas, pero afeminado, jamás.

Como ya hemos podido observar, y en clara confirmación de la efectividad de la ley de Murphy en el plano literario, son los personajes más memorables de Chaucer los que tal vez han pasado con más frecuencia y más minuciosidad por el tamiz de 
traductores y editores con casta iniciativa. El ebrio molinero, fiel a su naturaleza baja y grosera, relata un cuento de infidelidad en el que el mañoso estudiante Nicolás seduce a Alisón, esposa de un carpintero cornudo. La vivaz chica a su vez da entrada a Absolón, refinado mancebo de exquisitos, aunque a veces desafortunados, gustos. En uno de los ilícitos encuentros entre Alisón y Nicolás, éste "prively caughte hire by the queynte", es decir, "con disimulo la agarró por el coño", como, por una parte, traduce atinadamente Pedro Guardia en la edición de Bosch (1978: 253), mientras que, por otro lado, se censura a sí mismo al traducir "Con disimulo la palpó en sus partes" (140), en la versión de Cátedra (eufemismo que favorecen Serrano y León en la edición de Gredos: 137). En otro tono, la traducción de Porrúa no requiere mayor comentario: "[Nicolás] asió, pues, a solas, sus encantos..." (47).

Mención aparte merece la descripción de Absolón, quien, virtuoso y en extremo preocupado por su apariencia, "was somdeel squaymous of fartying and of speche daungerous" (50, vv. 3337-8), que Serrano y León traducen como "se escandalizaba fácilmente de las ventosidades, así como del habla violenta" (139). De Luaces favorece también las ventosidades, mientras que Guardia, en escandaloso error, convierte a nuestro encantador Absolón en un tipo "pesado" que "lanzaba pedos y era de conversación latosa" (141).

Al avanzar el cuento, y mientras Nicolás y Alisón se encuentran juntos en la cama, Absalón decide tomar medidas para conquistar a la hermosa muchacha, por lo cual decide acudir a su ventana, como buen caballero. Ella, para alejarlo de una vez por todas, promete asomarse para darle un beso en la total oscuridad de la noche. Menuda sorpresa se lleva Absolón cuando "at the window out she putte hir hole, / And Absolon [...] kiste hir naked ers / Ful savourly, er he were war of this" (53, vv. 3731-35). Es decir, "Absalón, lleno de sentimiento y sin sospechar lo más mínimo, con su boca besó muy sabrosamente su culo desnudo", como traducen Serrano y León (147). Y sin embargo, para Guardia, lo que Alisón saca por la ventana son simplemente "las posaderas" (150), término que en boca de un personaje cuya expresión "was moost of synne and of harlotries" resultaría muy poco probable.

Dadas estas irreverencias del cuento del molinero, no sorprende que al menos uno de los demás peregrinos se sienta ofendido: el administrador, carpintero él mismo, toma muy a pecho el que alguien que comparte su oficio resulte un cornudo estulto en el cuento que todos acaban de escuchar. La solución al agravio es la venganza en los mismos términos poético-narrativos. Se entiende entonces que el fabliau del administrador trate sobre un molinero deshonesto y ladrón, quien pretende engañar a dos estudiantes de Cambridge, Alano y Juan, con cantidades dudosas de grano. Los muchachos se vengan de la peor manera posible: se acuestan con la hija y la mujer del molinero, haciéndolo quedar en absoluto ridículo.

Pero aparentemente, la lúdica y lasciva situación no ofende sólo al molinero del cuento; algunos traductores se ven en la necesidad de "ajustar" sus versiones del que tal vez sea uno de los relatos más hilarantes de Los cuentos de Canterbury. Así pues, Juan cuenta a Alano sus planes para con la hija del molinero: "For John", seyde he, "als 


\section{$30 \square$ LOS CUENTOS DE CANTERBURY}

evere moot I thryve, / If that I may, yon wenche wil I swyve" (58, vv. 4177-78). Según el diccionario Oxford, "swive" es un término arcaico o humorístico para referirse a la relación sexual (1989, 17: 18762). El improperio que, en boca de Juan es evidente, para Guardia Massó queda como "te aseguro, Juan, que intentaré trabajarme a esa chica si puedo" (303) en la edición de Bosch, traducción que se conserva en la de Cátedra. Serrano y León son quizá los más atinados al ofrecernos: "te aseguro que, si puedo, voy a follarme a la joven moza" (159), mientras que, para De Luaces, el pícaro Juan habrá simplemente de "refocilarse" con la moza (62). ${ }^{6}$

Igualmente, y en cuanto a otras opciones — ora fieles ora inusitadas — para traducir los términos relacionados con la cópula, tenemos que, aunque al llegar a la moraleja de su cuento, el administrador nos dice:

Thus is the proude millere wel ybete,

An hath ylost the gryndynge of the whete,

And payed for the soper everydeel

Of Aleyn and of John, that bete hym wel.

His wyf is swived, and his doghter als.

Lo, swich it is a millere to be fals!

(60, vv. 4313-4318)

Serrano y León, quienes anteriormente no habían tenido empacho en usar el españolísimo término "follar", ahora traducen: "De esta manera el orgulloso molinero quedó maltrecho, perdió la molienda del trigo y pagó toda la cena de Alano y Juan, quienes también le zurraron bien. Su mujer fue jodida y también su hija. ¡Eso le ocurre al molinero por ser falso!" (162) La palabra "joder", aunque también vulgar y tal vez referente al perjuicio en contra del molinero, no alcanza la altisonancia del "follar" anterior, aunque en inglés medio "swyven" siga siendo el término para referirse al acto. Guardia, por otra parte, deja de lado "trabajar" para presentarnos: "Le jodieron a la mujer y a la hija" (164) mientras que De Luaces, con su ya demostrada prudencia, traduce: "Su mujer quedó deshonrada y su hija lo mismo" (64). Lo que para el administrador de Chaucer es abierta y bastamente sexual en un contexto picaresco (lo cual hace a este fabliau un más que digno representante de su género) en la traducción de Porrúa se ha convertido en cuento de mediana simpatía entre un molinero bonachón y dos estudiantes más decentes de lo que en realidad deberían ser.

Aunque George Steiner sostiene que, en traducción, "la transferencia no tiene que ser absoluta", también sugiere que "la equivalencia (en la sustitución que representa la traducción) se procura sustituyendo los signos verbales del original por otros 'iguales"” (1998: 460). Por supuesto, hay niveles de "igualdad" en toda traducción, y las transferencias de Chaucer al castellanos son, claramente, instancia indiscutible de esto. Basten por ahora los ejemplos anteriores para darnos cuenta de las tendencias en cuanto

\footnotetext{
${ }^{6}$ Según el DRAE, "refocilar" significa, de manera por demás general, "regodearse, recrearse en algo grosero" (2001, 2: 1925).
} 
a traducción de Los cuentos de Canterbury: la más equivalente, al menos en cuanto a indecencias y humor sexual, se la debemos a Serrano y León; Guardia Massó, aunque con algunos equívocos, nos ofrece un par de versiones que oscilan entre lo mesurado del traductor y la zafiedad de algunos de los personajes y, finalmente, De Luaces nos deja bastante insatisfechos con un ejemplo claro de mojigatería y censura entre quienes han escogido el oficio de traductores. Sobre todo en este último caso, como en aquella declamación a contrapelo de Los cuentos de Canterbury ante las vacas, Chaucer suena perdido, y la voz de sus personajes, al igual que las voces de otros protagonistas, pierden color a medida que todos ellos se van haciendo víctimas de un recato que, si en el siglo XIV afortunadamente no acalló a Chaucer, en el siglo XX - y hasta en el XXI- no tendría por qué parcializar a algunos de sus traductores al castellano. Es deseo de quien escribe que nuevas traducciones no nos hagan quedar a los lectores como al ganado de Ted Hughes: absortos, esperando que alguien o algo nos revele los significados de una voz ajena, sí, aunque en definitiva deslumbrante.

\section{Obras citadas}

BuenO AlONSO, Jorge Luis. 2001. < http://www.atlantisjournal.org/Papers/25_1/123128 Bueno.pdf>

Chaucer, Geoffrey. 1978. Cuentos de Canterbury. Ed. y trad. Pedro GuARdia Massó. Barcelona: Bosch. (Letras universales)

. 1979. The Complete Works of Geoffrey Chaucer. Ed. F. N. RoBINSON. Oxford: Oxford University Press. . 1992. Cuentos de Canterbury. Trad. Juan DE LuACES. México: Porrúa. (Sepan cuántos...)

. 2001. Cuentos de Canterbury. Ed. y trad. Pedro GuARdia Massó. Madrid: Cátedra. (Erasmo, textos bilingües)

. 2004. Los cuentos de Canterbury. Ed. y trad. Jesús L. SERRANo ReYeS y

Antonio R. LEÓN SANDRA. Madrid: Gredos. (Biblioteca universal)

Diccionario de la Lengua Española. 2001. 2 vols. 22a. ed. Madrid: Real Academia Española.

Eighteenth-Century Modernizations from the Canterbury Tales. 1991. Ed. Betsy BowDEN. Rochester, NY: D.S. Brewer.

HugHES, Ted. 1998. Birthday Letters. Londres: Faber and Faber.

Oxford English Dictionary. 1989. 20 vols. 2a. ed. Nueva York: Oxford University Press.

PARKInSON, Justin. "Chaucer's tales become rap songs". BBC News. 28 de julio de $2005<\mathrm{http}: / /$ news.bbc.co.uk/1/hi/education/4721073.stm>

Princeton Encyclopedia of Poetry and Poetics. 1990. Ed. Alex PREMINGER. Princeton: Princeton University Press.

STEINER, George. 1998. After Babel. Aspects of Language and Translation. Oxford: Oxford University Press. 